Article

\title{
Investigation of Effective Modification Treatments for Titanium Membranes
}

\author{
Reiko Kobatake, Kazuya Doi *, Yoshifumi Oki, Hanako Umehara, Hiromichi Kawano, \\ Takayasu Kubo and Kazuhiro Tsuga
}

Department of Advanced Prosthodontics, Hiroshima University Graduate School of Biomedical and Health Sciences; 1-2-3, Kasumi, Minami-ku, Hiroshima 734-8553, Japan; reiko1122@hiroshima-u.ac.jp (R.K.); yos-oki14@hiroshima-u.ac.jp (Y.O.); hanako-ume@hiroshima-u.ac.jp (H.U.); h-kawano0321@hiroshima-u.ac.jp (H.K.); kubocky@hiroshima-u.ac.jp (T.K.); tsuga@hiroshima-u.ac.jp (K.T.)

* Correspondence: kazuya17@hiroshima-u.ac.jp; Tel.: +81-82-257-5677; Fax: +81-82-257-5679

Received: 4 September 2017; Accepted: 2 October 2017; Published: 4 October 2017

\begin{abstract}
Titanium membranes are used for guided bone regeneration in implant therapy. However, as a bioinert material, titanium does not have the ability to accelerate bone formation. Various titanium surface treatments to confer bioactivity have been demonstrated; however, there are concerns about the influence of chemical treatments for thin titanium membranes. This study investigated the influence of surface modifications on the structure of titanium membranes. Titanium membranes of $20 \mu \mathrm{m}$ thickness were treated with acid or alkali solutions, and we evaluated their surface structure, wettability, thickness, and mechanical strength compared to non-treated membranes. Alkali-treated titanium membranes displayed the formation of nanoscale pore structures on their surfaces, enhanced hydrophilicity, and almost same thickness compared with acid-treated membranes. Furthermore, the tensile strength of alkali-treated membranes was comparable to non-treated membranes. These results suggest that alkali treatment is an appropriate surface modification method for titanium membranes.
\end{abstract}

Keywords: titanium membrane; surface modification; alkali treatment

\section{Introduction}

The existence of sufficient bone volume is a factor for successful treatment with dental implants [1]. In cases with insufficient bone volume at the implant placement site due to bone absorption or trauma, implant threads can be partially exposed when the implant is placed into the bone tissue, and in these cases, guided bone regeneration (GBR) is applied to augment the bone tissue [2,3]. Barrier membranes play a crucial role in GBR, because epithelial tissues recover more quickly than bone, and can invade into the space required for new bone formation and inhibit the process. Therefore, positioning the barrier membrane at the interface between the epithelium and periosteum retains the space required for bone healing.

Absorbent membranes such an atelocollagen or polyglycolic acid display excellent operability and do not require removal, and are used as barrier membranes in periodontal therapy. These absorbent membranes are suitable for small bone defects; however, their application to the grafting of large bone defects is problematic because of their insufficient mechanical strength $[4,5]$. Non-absorbent membranes like those made from titanium are superior in mechanical strength to absorbent membranes.

Titanium membranes are used as barrier membrane for GBR because of their superior biocompatibility, mechanical strength, and operability. Therefore, various studies have demonstrated that they make and retain space well in grafts of large bone defects [6-8]. However, titanium does not have the ability to accelerate bone formation because it is bioinert $[9,10]$. It is well known that titanium surface topography can be improved by various modification methods, including grit blasting with 
sand or ceramic particles, acid etching, titanium plasma spraying, plasma spray coating, and other methods [11,12]. Improved titanium surfaces have bioactive ability, and can promote cell adhesion and osteoinduction [13-15]. In particular, chemical methods such as acid etching or alkali treatment are often used because of their simplicity [16-19]. A titanium surface modified by a strong acid or alkali solution can form an apatite layer when soaked in body fluid $[17,20,21]$. For this reason, these modified treatments are already being applied as dental implants and titanium plates used in bone reconstruction. Therefore, the creation of bioactive thin titanium membranes would be beneficial for GBR.

Chemical treatments corrode the titanium surface, making it rough, extremely hydrophilic, and suitable for bone formation [22]. The structural change of chemical treatment is not a serious problem for solid titanium materials such as implant fixtures. However, the effects of these treatments on the surfaces of titanium membranes are not well established, and they may influence the structure and mechanical strength of these membranes. The purpose of this study was to investigate the influence of surface modification treatments on the mechanical strength and structure of titanium membranes.

\section{Methods}

\subsection{Sample Preparation}

Titanium membranes are manufactured through the extension of a titanium metal mass by applying pressure through the gap between two rollers, until the targeted thickness is achieved. Titanium membranes (thickness of $20 \mu \mathrm{m}, 10 \times 10 \mathrm{~mm}$ square) were used for surface modification in this study (Figure 1).

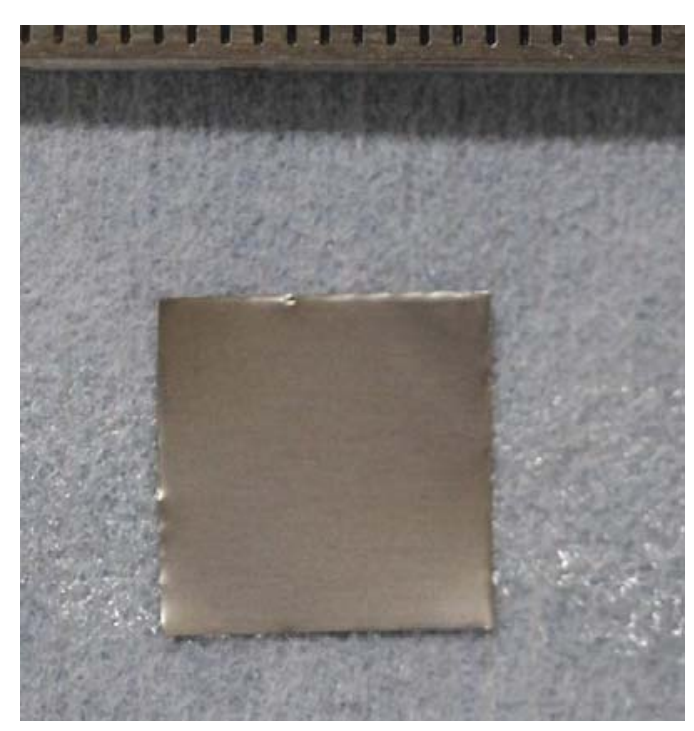

Figure 1. Titanium membrane.

The membranes were washed in an ultrasonic cleaner with acetone and distilled water for $60 \mathrm{~min}$ each and dried in a $37^{\circ} \mathrm{C}$ oven. Then, membranes were divided into three groups: acid, alkali, and control. For the acid group, membranes were soaked in a 1:1 $(w / w)$ solution of $66.3 \% \mathrm{H}_{2} \mathrm{SO}_{4}(w / w)$ (NACALAI TESQUE, Inc., Kyoto, Japan) and $10.6 \% \mathrm{HCl}(w / w)$ (NACALAI TESQUE, Inc., Kyoto, Japan) at $60^{\circ} \mathrm{C}$ for $60 \mathrm{~min}$, with gentle shaking. The volume of the solution was $20 \mathrm{~mL} / \mathrm{membrane}$. After incubation, the membranes were washed with distilled water and dried in a $37^{\circ} \mathrm{C}$ oven. For the alkali group, membranes were soaked in $5 \mathrm{~N} \mathrm{NaOH}$ solution (NACALAI TESQUE, Inc., Kyoto, Japan) and incubated as above for $24 \mathrm{~h}$, then washed and dried. For the control group, membranes were washed with distilled water and dried in a $37^{\circ} \mathrm{C}$ oven. 


\subsection{Scanning Electron Microscopy (SEM)}

For surface structure assessment, a square sample from each group was attached to a sample stage with carbonate adhesive tape and imaged by scanning electron microscope (SEM, JSM-6010PLUS/LA, Nihon Denshi Oyo Co., Ltd. Tokyo, Japan) at an accelerating voltage of $15 \mathrm{kV}$, working distance of 9-10 $\mathrm{mm}$, and spot size of 40 and 60 . Samples were evaluated by measuring the central thickness of the samples.

\subsection{Thickness}

Each membrane thickness was measured by digital micro meter instrument (MDH-25M, Mitutoyo Co., Ltd. Kanagawa, Japan) (Figure 2). The value of thickness was compared before and after treatment.

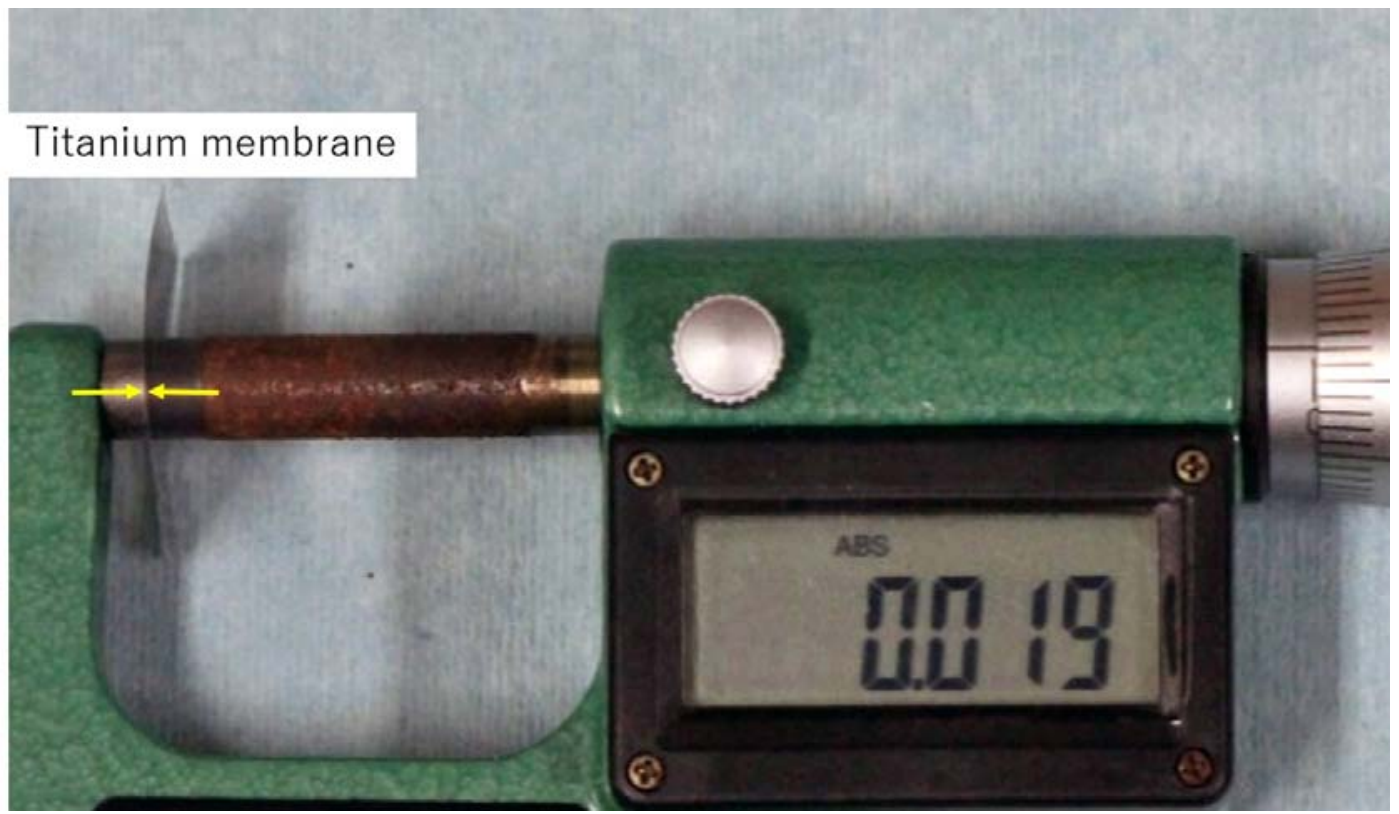

Figure 2. Measurement of thickness. Between yellow arrows indicate of sample thickness.

\subsection{Tensile Strength}

Mechanical strength evaluation used a rectangular membrane from each group. Both the top and bottom sides of each membrane were fixed to the testing machine (AUTO GRAPH AGS-X, Shimadzu), and the samples were pulled at a constant speed $(5 \mathrm{~mm} / \mathrm{min})$ until their breaking points were reached. The maximum tensile stress value was used to represent the mechanical strength of the membrane.

\subsection{Evaluation of Wettability}

First, each square membrane sample was divided into four $10 \mu \mathrm{m}$ squares, which were fixed to the stage. Then, a $10-\mu \mathrm{L}$ drop of pure water was gently applied to each sample. Ten seconds after the water and the membrane touched, an image was taken with an S-image device. Then, the contact angles of the dropped water were measured using ImageJ (National Institutes of Health, Bethesda, Maryland, USA). These were obtained using a half-angle method, by measuring the angle of the straight line connecting the end point and the vertex of the droplet, and then doubling this value.

\subsection{Statistical Analyses}

All data were analyzed at the $5 \%$ significance level using one-way analysis of variance followed by Tukey's test, and are expressed as the mean \pm standard deviation (SD). 


\section{Results}

\subsection{SEM Observations}

SEM images of the surface structure of samples from each group are shown in Figure 3. The control group displayed a non-uniform, rough surface (Figure 3a). At high magnification, grooves and indentations were detected, but pore structures were not observed (Figure 3b). The acid group displayed a uniform, rough surface (Figure 3c), which contained microscale pore structures (Figure 3d). The alkali group had a similar structure to the control group, with grooves and indentations (Figure 3e). At high magnification, nanoscale pore structures were observed on the surface, and these structures formed a network (Figure 3f).
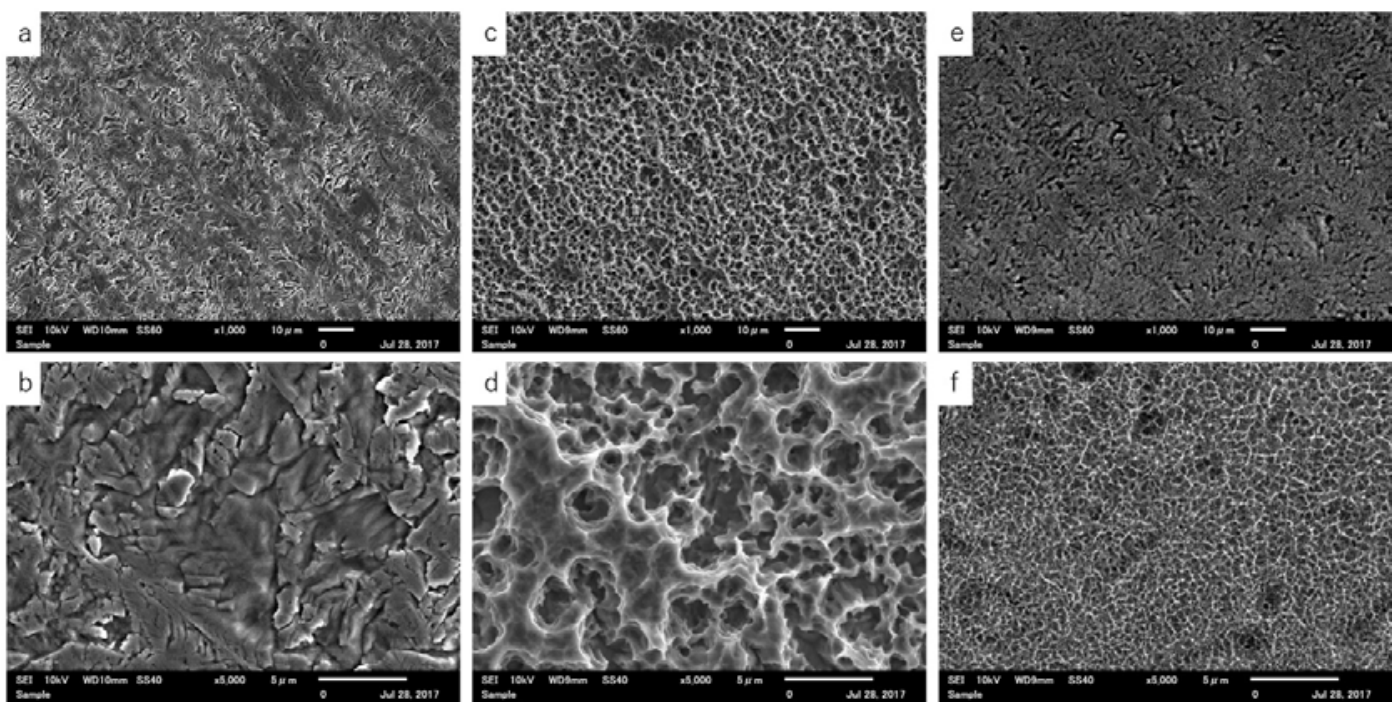

Figure 3. SEM images of each sample. Control group: (a) $1000 \times$ displayed a non-uniform, rough surface; (b) 5000× had grooves and indentations, but no pore structures. Acid group: (c) $1000 \times$ displayed a uniform, rough surface; (d) $5000 \times$ contained microscale pore structures. Alkali group: (e) $1000 \times$ had a similar structure to the control group, with grooves and indentations; (f) $5000 \times$ had nanoscale pore structures.

\subsection{Thickness}

Table 1 shows the thickness of each sample. The acid group was significantly thinner compared to the other groups, while the thickness in the alkali group was comparable to the control.

Table 1. Thickness of samples.

\begin{tabular}{cc}
\hline Surface Treatment & Thickness $(\mu \mathrm{m})(\mathrm{SD})$ \\
\hline control (non-treated) & $20.0 \pm 0.75$ \\
acid & $15.1 \pm 0.64^{*}$ \\
alkali & $19.7 \pm 0.46$ \\
\hline
\end{tabular}

SD: standard deviation; ${ }^{*} p<0.001$ vs. other groups.

\subsection{Tensile Strength}

Table 2 shows the tensile strength of each sample. The tensile strength was significantly decreased by acid treatment. Conversely, there was no significant difference in strength between the alkali and control groups, indicating that alkali treatment did not weaken the membranes. 
Table 2. Tensile strength of samples.

\begin{tabular}{cc}
\hline Surface Treatment & Maximum Tensile Strength (N) (SD) \\
\hline control (non-treated) & $309.5 \pm 29.3$ \\
acid & $158.4 \pm 20.2^{*}$ \\
alkali & $295.0 \pm 48.3$ \\
\hline
\end{tabular}

SD: standard deviation; ${ }^{*} p<0.001$ vs. other groups.

\subsection{Evaluation of Wettability}

Figure 4 shows the shapes of the water drops applied to each sample. The water drop on the control membrane had a semicircular shape and was slightly extended (Figure 4a). The drop on the acid-treated membrane had a round shape and was not extended (Figure $4 \mathrm{~b}$ ), while the drop of water on the alkaline membrane was extended dramatically, and is not visible in the image in Figure 4c. Table 3 shows the contact angle of each sample. The angle in the alkali group was not determined and suggesting that the alkali membranes had strongly hydrophilic condition.

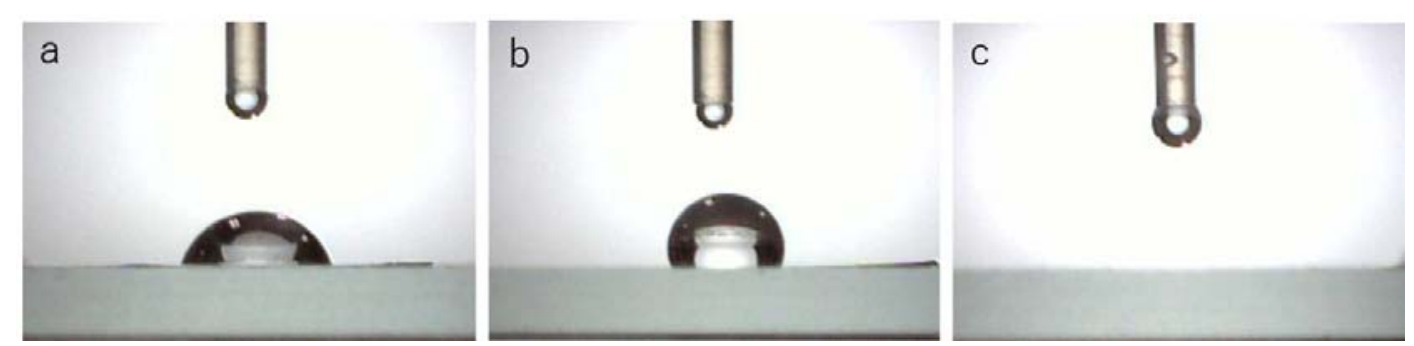

Figure 4. The shapes of the water drops applied to each sample. (a) Control; (b) Acid; (c) Alkali group.

Table 3. Contact angle.

\begin{tabular}{cc}
\hline Surface Treatment & Contact Angle $\left(^{\circ}\right)(\mathrm{SD})$ \\
\hline control (non-treated) & $71.1 \pm 1.63^{*}$ \\
acid & $103.1 \pm 3.81$ \\
alkali & not determined
\end{tabular}

SD: standard deviation; * significant differences in each group respectively; $p<0.001$.

\section{Discussion}

To regenerate large sections of bone, the GBR membrane needs to be malleable enough to easily conform to bone morphology, and have adequate mechanical strength to maintain its form until the new bone has formed. There is a correlation between mechanical strength and thickness-thicker membranes have higher strength [23]. However, thick membranes are less flexible and formable, creating sharp edges when cutting, trimming, and bending them along the defect site. Thick membranes show less tissue adhesion, which permits penetration of soft tissue from the gap, preventing new bone formation. Thin membranes follow the bone morphology and do not create air pockets, which is advantageous for bone formation. However, with decreased mechanical strength, membranes can collapse into the defect cavity, decreasing the bone formation space and consequently the volume of new bone formed. There are reports that membranes of 100 to $200 \mu \mathrm{m}$ thickness are suitable for healing large-scale bone defects [24]. However, the lack of flexibility of membranes of this thickness gives them poor operability. An advantage of titanium membranes is that they maintain their mechanical strength even when thin. A thickness of $20 \mu \mathrm{m}$ is most suitable for GBR treatment, and accordingly, commercially available and clinically applied titanium membranes are $20 \mu \mathrm{m}$ thick. Our experiments were conducted with membranes of this thickness as well. As mentioned above in 
the methods section, titanium membranes were manufactured through the extension of a titanium metal mass by applying pressure through the gap between two rollers. Consequently, the surface topography of non-treated membranes had a roughened structure. In the study, we used acid and alkali treatments for surface modification. Titanium exerts corrosion resistance by forming an oxide layer on the surface; however, it is corroded by non-oxidizing acid solutions such as $\mathrm{H}_{2} \mathrm{SO}_{4}$ and $\mathrm{HCl}$ [25]. Van Gestel et al. [26] reported that corrosion is mainly due to dissolution of the membrane material-especially in acid solutions with a $\mathrm{pH}<3$. This corrosion is considered to change the surface structure and thickness of the titanium membrane. The surface of the acid treatment showed a regularly rough surface with micro scale pore structures. Although a rough surface was created on the titanium surface, the irregular rough surface and grooves which were observed in the non-treated sample were not detected. This is attributed to the fact that corrosion by strong acid slightly changed and smoothed the topography rather than providing the irregularly roughed non-treatment membrane. The effect of acid treatment was also reflected in membrane thickness. Thickness and mechanical tensile strength of acid treatment were significantly decreased compared with non-treated membrane and alkali membrane. Also, the SEM image appeared different surface topography, according to the results of thickness and tensile strength measurements.

Several studies have reported that acid treatment modifies the wettability of titanium surfaces $[12,22]$. In wettability test, the contact angle of acid treatment was significantly higher than non-treated and alkali treatment. Currently, we have no clear explanation for this discrepancy. However, these past studies were performed using finely polished, smoothly surfaced titanium disks as control samples. In our study, the control membrane had an irregular rough surface caused by the manufacturing process. Thus, acid treatment seems to have altered the titanium membrane from a rough surface to a smooth surface, and the acid membrane showed a high contact angle. These results indicated that acid treatment slightly changed the rough surface and reduced the mechanical strength of the titanium membrane.

Conversely, the surface of alkali-treated membranes created uniformly nanoscale pore structures on the rough surface, and this structure was consistent with that of previous reports [21,27]. The alkali-treated membranes displayed enhanced hydrophilicity, which may be attributed to the nanoscale pore structure. Increased hydrophilicity promotes cell adhesion and nutrient supply, and is advantageous for bone regeneration [28]. Previous studies have compared alkali-and acid-treated implants, and found that implants treated with alkali displayed enhanced mineralization of the implant surface [29]. These results indicate that alkali treatment produces a hydrophilic topography with a nanoscale pore network. Additionally, titanium exerts corrosion resistance for alkali solution because of an oxygen layer on the surface. For these reasons, the influence of alkali treatment on the strength and thickness of titanium membranes was only slight.

\section{Conclusions}

The acid treatment reduced the thickness and mechanical strength of the titanium membrane, and did not modify the surface to hydrophilic. On the other hand, the alkali treatment did not affect the thickness and mechanical strength, and improved the surface to super hydrophilic. Our results suggest that alkali treatment is an appropriate titanium membrane surface modification method for the development of bioactive titanium membranes.

Author Contributions: Conceived and designed experiments: Kazuya Doi, Reiko Kobatake. Performed experiments: Kazuya Doi, Reiko Kobatake, Yoshifumi Oki. Analyzed the data: Hanako Umehara, Hiromichi Kawano. Contributed reagents/materials/analysis tools: Kazuya Doi, Reiko Kobatake, Takayasu Kubo. Wrote the paper: Kazuya Doi, Reiko Kobatake, Kazuhiro Tsuga.

Conflicts of Interest: The authors declare no conflict of interest. 


\section{References}

1. Johansson, B.; Bäck, T.; Hirsch, J.M. Cutting torque measurements in conjunction with implant placement in grafted and nongrafted maxillas as an objective evaluation of bone density: A possible method for identifying early implant failures? Clin. Implant Dent. Relat. Res. 2004, 6, 9-15. [CrossRef] [PubMed]

2. Hämmerle, C.H.F.; Karring, T. Guided bone regeneration at oral implant sites. Periodontology 1998, 17, 151-175. [CrossRef]

3. Chiapasco, M.; Casentini, P.; Zaniboni, M. Bone augmentation procedures in implant dentistry. Int. J. Oral Maxillofac. Implants 2009, 24, 237-259. [PubMed]

4. Becker, W.; Becker, B.; Mellonig, J. A prospective multicenter study evaluating periodontal regeneration for class II furcation invasions and infrabony defects after treatment with a bioabsorbable barrier membrane: 1-Year results. J. Periodontol. 1996, 67, 641-649. [CrossRef] [PubMed]

5. Zitzmann, N.U.; Naef, R.; Scharer, P. Resorbable versus nonresorbable membranes in combination with Bio-Oss for guided bone regeneration. Int. J. Oral Maxillofac. Implants 1997, 12, 844-852. [PubMed]

6. Zablotsky, M.; Meffert, R.; Caudill, R. Histological and clinical compar-isons of guided tissue regeneration on dehisced hydroxylapatite-coated and titanium endosseous implant surfaces. A pilot study. Int. J. Oral Maxillofac. Implants 1991, 6, 294. [PubMed]

7. Wang, R.R.; Fenton, A. Titanium for prosthodontic applications: A review of the literature. Quintessence Int. 1996, 27, 401-408. [PubMed]

8. Degidi, M.; Scarano, A.; Piattelli, A. Regeneration of the alveolar crest using titanium micromesh with autologous bone and a resorbable membrane. J. Oral Implantol. 2003, 29, 86. [CrossRef]

9. Cole, B.J.; Bostrom, M.P.; Pritchard, T.L.; Sumner, D.R.; Tomin, E.; Lane, J.M.; Weiland, A.J. Use of bone morphogenetic protein 2 on ectopic porous coated implants in the rat. Clin. Orthop. Relat. Res. 1997, 345, 219-228. [CrossRef]

10. Ferretti, C.; Ripamonti, U. Human segmental mandibular defects treated with naturally derived bone morphogenetic proteins. J. Craniofac. Surg. 2002, 13, 434-444. [CrossRef] [PubMed]

11. Le Guéhennec, L.; Soueidan, A.; Layrolle, P.; Amouriq, Y. Surface treatments of titanium dental implants for rapid osseointegration. Dent. Mater. 2007, 23, 844-854. [CrossRef] [PubMed]

12. Jemat, A.; Ghazali, M.J.; Razali, M.; Otsuka, Y. Surface Modifications and Their Effects on Titanium Dental Implants. BioMed Res. Int. 2015, 2015, 791725. [CrossRef] [PubMed]

13. Kim, H.M.; Miyaji, F.; Kokubo, T.; Nakamura, T. Preparation of bioactive Ti and its alloys via simple chemical surface treatment. J. Biomed. Mater. Res. 1996, 32, 409-417. [CrossRef]

14. Nishiguchi, S.; Kato, H.; Fujita, H.; Kim, H.M.; Miyaji, F.; Kokubo, T.; Nakamura, T. Enhancement of bone-bonding strengths of titanium alloy implants by alkali and heat treatments. J. Biomed. Mater. Res. 1999, 48, 689-696. [CrossRef]

15. Fujibayashi, S.; Nakamura, T.; Nishiguchi, S.; Tamura, J.; Uchida, M.; Kim, H.M.; Kokubo, T. Bioactive titanium: Effect of sodium removal on the bone-bonding ability of bioactive titanium prepared by alkali and heat treatment. J. Biomed. Mater. Res. 2001, 56, 562-570. [CrossRef]

16. Takemoto, M.; Fujibayashi, S.; Neo, M.; Suzuki, J.; Matsushita, T.; Kokubo, T.; Nakamura, T. Osteoinductive porous titanium implants: Effect of sodium removal by dilute $\mathrm{HCl}$ treatment. Biomaterials 2006, 27, 2682-2691. [CrossRef] [PubMed]

17. Kokubo, T.; Miyaji, F.; Kim, H.M. Spontaneous formation of bone like apatite layer on chemically treated titanium metals. J. Am. Ceram. Soc. 1996, 79, 1127-1129. [CrossRef]

18. Kim, H.M.; Miyaji, F.; Kokubo, T.; Nakamura, T. Effect of heat treatment on apatite-forming ability of Ti metal induced by alkali treatment. J. Mater. Sci. Mater. Med. 1997, 8, 341-347. [CrossRef] [PubMed]

19. Ban, S.; Iwaya, Y.; Kono, H.; Sato, H. Surface modification of titanium by etching in concentrated sulfuric acid. Dent. Mater. 2006, 22, 1115-1120. [CrossRef] [PubMed]

20. Kono, H.; Miyamoto, M.; Ban, S. Bioactive Apatite coating on titanium using an alternate soaking process. Dent. Mater. J. 2007, 26, 186-193. [CrossRef] [PubMed]

21. Kawai, T.; Takemoto, M.; Fujibayashi, S.; Akiyama, H.; Tanaka, M.; Yamaguchi, S.; Pattanayak, D.K.; Doi, K.; Matsushita, T.; Nakamura, T.; et al. Osteoinduction on acid and heat treated porous Ti metal samples in canine muscle. PLoS ONE 2014, 9, e88366. [CrossRef] [PubMed] 
22. Iwaya, Y.; Machigashira, M.; Kanbara, K.; Miyamoto, M.; Noguchi, K.; Izumi, Y.; Ban, S. Surface properties and biocompatibility of acid-etched titanium. Dent. Mater. J. 2008, 27, 415-421. [CrossRef] [PubMed]

23. Rakhmatia, Y.D.; Ayukawa, Y.; Jinno, Y.; Furuhashi, A.; Koyano, K. Micro-computed tomography analysis of early stage bone healing using micro-porous titanium mesh for guided bone regeneration: Preliminary experiment in a canine model. Odontology 2017. [CrossRef] [PubMed]

24. Vovk, V.; Vovk, Y. Results of the guided bone regeneration in patients with jaw defects and atrophies by means of Mondeal ${ }^{\circledR}$ occlusive titanium membranes. J. Oral Maxillofac. Surg. 2005, 34, 74. [CrossRef]

25. Juodzbalys, G.; Sapragoniene, M.; Wennerberg, A. New acid etched titanium dental implant surface. Stomatologija 2003, 5, 101-105.

26. Van Gestel, T.; Vandecasteele, C.; Buekenhoudt, A.; Dotremont, C.; Luyten, J.; Van der Bruggen, B.; Maes, G. Corrosion properties of alumina and titania NF membranes. J. Membr. Sci. 2003, 214, 21-29. [CrossRef]

27. Camargo, W.A.; Takemoto, S.; Hoekstra, J.W.; Leeuwenburgh, S.C.G.; Jansen, J.A.; van den Beucken, J.J.J.P.; Alghamdi, H.S. Effect of surface alkali-based treatment of titanium implants on ability to promote in vitro mineralization and in vivo bone formation. Acta Biomater. 2017, 57, 511-523. [CrossRef] [PubMed]

28. Dalby, M.J.; McCloy, D.; Robertson, M.; Wilkinson, C.D.; Oreffo, R.O. Osteoprogenitor response to defined topographies with nanoscale depths. Biomaterials 2006, 27, 1306-1315. [CrossRef] [PubMed]

29. Tugulu, S.; Löwe, K.; Scharnweber, D.; Schlottig, F. Preparation of superhydrophilic microrough titanium implant surfaces by alkali treatment. J. Mater. Sci. Mater. Med. 2010, 21, 2751-2763. [CrossRef] [PubMed]

(C) 2017 by the authors. Licensee MDPI, Basel, Switzerland. This article is an open access article distributed under the terms and conditions of the Creative Commons Attribution (CC BY) license (http://creativecommons.org/licenses/by/4.0/). 